\title{
Dinâmica da interação professor-estudante em contexto de ensino superior: Construção e estudo exploratório do questionário da interação
}

\author{
professor-estudante
}

\section{Dynamics of teacher-student interaction in higher education: Design and exploratory study of the teacher-student interaction questionnaire}

\author{
Sofia de Lurdes Rosas da Silva*, Joaquim Armando Gomes Ferreira**, António Gomes Ferreira** \\ *Escola Superior de Educação - Instituto Politécnico de Coimbra, *,*GRUPOEDE - CEIS XX, Portugal, **Faculdade de Psicologia e \\ de Ciências da Educação da Universidade de Coimbra
}

\begin{abstract}
Resumo
O presente estudo procurou, a partir da análise das perceções de professores e estudantes do ensino superior sobre o que são para si interações de qualidade, construir o Questionário da Interação Professor-Estudante (QIPE). Para o efeito, partimos da análise de conteúdo de entrevistas realizadas junto de 31 estudantes e de 21 professores e do seu confronto com a literatura. A versão final do QIPE resultou numa solução de três fatores, com um nível de consistência interna bastante aceitável: Gestão da Relação Pedagógica $(\alpha=.90)$, Contacto com os Professores $(\alpha=.87)$ e Perceção de Suporte $(\alpha=.84)$.

Palavras chave: interação professor-estudante, questionário, estudo exploratório.
\end{abstract}

\begin{abstract}
The present study sought to design the Teacher-Student Interaction Questionnaire (QIPE) from the analysis of higher education teachers and students' perceptions on what quality interactions were for them. For this purpose, we started with the content analysis of 31 students and 21 teachers interviews and their confrontation with the literature. The final version of the QIPE resulted in a solution of three factors, with very acceptable levels of internal consistency: Pedagogical Interaction Management $(\alpha=.90)$, Contact with Teachers $(\alpha=.87)$ and Support Perception $(\alpha=.84)$.

Keywords: teacher-student, interaction, questionnaire, exploratory study.
\end{abstract}

\section{Introdução}

As interações entre professores e estudantes em contexto de ensino superior têm recebido atenção especial de um grupo considerável de investigadores. Em particular, tem-se defendido que ambientes institucionais apoiantes e com interações positivas entre professores e estudantes estimulam o sucesso académico e o desenvolvimento psicossocial dos estudantes (Cole, 2008; Kuh, Kinzie, Buckley, Bridges, \& Hayek, 2006; Pascarella \& Terenzini, 2005; Silva, 2012; Silva, Ferreira, \& Ferreira, 2011).
A pesquisa sobre o tipo e a qualidade das interações entre professores e estudantes (Helterbran, 2008; Pascarella \& Terenzini, 2005; Silva, 2012; Silva, Ferreira, \& Ferreira, 2011) tem-se centrado nas interações que ocorrem na sala de aula e nas que se dão fora destes contextos formais, sendo assinaladas diversas práticas enriquecedoras e promotoras de interação em ambos os contextos, com impacto positivo no sucesso académico do estudante.

A procura de contacto junto do profesor por parte do estudante, para além do contexto da sala de aula, também tem recebido alguma atenção, tendo-se revelado que certos comportamentos do estudante (como a procura de informação relacionada com uma unidade curricular ou o solicitar comentários ou críticas a um trabalho) apresentam efeitos positivos na perceção de ganhos ao nível da aquisição de conhecimento e de competências académicas (Kuh \& Hu, 2001).

Outra linha de investigação mais centrada na análise de aspetos relacionados com o comportamento dos professores em relação à lecionação, refere-se às consequências positivas de tais comportamentos ao nível do rendimento académico dos estudantes e da aprendizagem por estes alcançada (Pascarella \& Terenzini, 2005). Tais comportamentos incluem, por exemplo, a atribuição de tarefas académicas significativas, a preparação e a organização das aulas, o entusiasmo, a disponibilidade para apoiar, a qualidade e frequência do feedback, etc.

Por outro lado, é frequente referir-se que o sucesso educativo dos estudantes reflete não só a qualidade das condições de ensino aprendizagem, como a qualidade das interações estabelecidas (Cashin, 1995; Silva, 2012). Entre esses aspetos, destaca-se uma dimensão mais interpessoal da relação professor-estudante, com uma função importante de satisfação de necessidades e de suporte (Serra, 2006), e que pode englobar aspetos como o interesse e disponibilidade do professor para apoiar e 
atitudes relacionais como a empatia e a autenticidade (Silva, 2012; Silva et al., 2011).

Face a este enquadramento, é pois, compreensível, que se procure construir instrumentos de avaliação da interação professor-estudante que possam ser utilizados também como ferramentas úteis no desenho de práticas educativas de qualidade.

Deste modo, os objetivos principais deste estudo foram: analisar as perceções de professores e estudantes de uma instituição de ensino superior politécnico sobre o que consideravam ser interações de qualidade; construir o Questionário da Interação Professor-Estudante (QIPE); e efetuar o estudo das suas qualidades métricas (dimensionalidade e consistência interna).

\section{Método}

Como referido, um dos objetivos desta investigação consistiu na construção de um instrumento de avaliação de autorrelato da Interação Professor-Estudante (QIPE) adaptado às características culturais de uma instituição do ensino superior politécnico.

Uma vez que assumimos que a interação professor-estudante é uma relação de interdependência, a construção do QIPE partiu de um estudo qualitativo que se centrou na análise de conteúdo de entrevistas individuais conduzidas junto de 21 professores e de 31 estudantes de uma instituição de ensino superior politécnico para conhecer que qualidades atribuíam e valorizavam nas suas interações. $\mathrm{O}$ nosso objetivo era perceber que categorias emergiam dos discursos dos participantes para descrever uma interação de qualidade.

A análise de conteúdo das entrevistas dos participantes acerca das suas interações permitiu-nos definir que categorias eram relevantes no contexto particular do estudo, tendo-se efetuado sempre o confronto com a literatura no domínio. A partir desta análise formularam-se as questões (itens) e tomaram-se decisões sobre o formato de resposta (escala de tipo likert de cinco pontos).

A primeira versão do instrumento foi testada com um grupo de 45 estudantes e o estudo exploratório, após alguns ajustes ao QIPE, foi conduzido com uma amostra de 576 estudantes.

Os pontos que se seguem referem-se aos procedimentos adotados e apresentam os estudos de validação utilizados.

\section{Sujeitos}

No pré-teste do QIPE participaram 45 estudantes (7 do sexo masculino e 38 do feminino), a frequentar o $1 .^{\circ}$ $(n=24), 2 .^{\circ} \quad(n=9)$ e $3 .^{\circ}$ ano $(n=12)$ de diversas licenciaturas (no domínio das Artes, Educação e Comunicação), com idades compreendidas entre os 17 e os 44 anos.

No estudo exploratório participaram 576 estudantes, do $1 .^{\circ}(\mathrm{n}=195), 2 .^{\circ}(\mathrm{n}=187)$ e $3 .^{\circ}$ ano $(\mathrm{n}=194)$. De salientar que a amostra é maioritariamente do sexo feminino $(\mathrm{n}=403 ; 70 \%)$, reflexo das características do contexto de estudo, e os estudantes do sexo masculino são significativamente mais velhos $(\mathrm{t}=2.497$; $\mathrm{p}<.05)$, em média um ano $(\mathrm{M}=21.57 \pm 3.75)$, do que os do sexo feminino $(\mathrm{M}=20.59 \pm 2.80)$.

\section{Procedimento}

Como referido, a construção do QIPE partiu da análise de conteúdo das entrevistas realizadas aos estudantes e aos professores e do confronto das categorias que foram emergindo dessa análise com os principais resultados da investigação no domínio.

Da análise de conteúdo emergiram as seguintes categorias: Proximidade, Apoio Educativo, Gestão Pedagógica e Contacto com os Professores. O confronto das fontes levou-nos a partir do pressuposto da possibilidade de multidimensionalidade do constructo.

Para avaliar o constructo foram elaborados itens que, na sua maioria, emergiram do conteúdo das entrevistas realizadas. Procedeu-se ainda a uma comparação com a literatura com o objetivo de refinar e completar o instrumento.

Neste processo também tiveram de ser tomadas decisões relativamente ao formato de resposta. A opção recaiu sobre a escala de likert de cinco pontos (nunca se verifica, poucas vezes se verifica, algumas vezes verifica-se e outras não, verifica-se bastantes vezes, verifica-se sempre).

Depois de elaborado, o QIPE foi inicialmente submetido a um pré-teste junto de um grupo de 45 estudantes, com os seguintes objetivos: 1) avaliar o nível de compreensibilidade das questões; 2) detetar questões inúteis ou redundantes; 3) identificar perguntas relevantes que estivessem ausentes; e 4) avaliar a qualidade gráfica do instrumento. Durante a administração desta versão, procedeu-se a uma reflexão falada dos itens (Freire \& Almeida, 2001).

Elaborada a versão final do QIPE, procedeu-se à sua administração junto de uma amostra de 576 estudantes com o objetivo de realizar um estudo exploratório que permitisse não apenas reduzir a extensão do instrumento, como também avaliar a sua dimensionalidade e respetiva consistência interna.

Para o efeito, efetuaram-se análises fatoriais exploratórias (método de extração em componentes principais, rotação ortogonal varimax) e análises da consistência interna dos fatores através do alpha de Cronbach. No ponto que se segue, apresentam-se os resultados.

\section{Resultados}

A versão inicial do QIPE era constituída por 39 itens distribuídos por 4 dimensões: Proximidade, Apoio Educativo, Gestão Pedagógica e Contacto com os Professores.

No que diz respeito à subescala Proximidade, esta era constituída por 9 itens que avaliam a perceção da existência de um relacionamento de proximidade com os professores, traduzida por sentimentos de "à vontade".

A subescala Apoio Educativo integra 7 itens que avaliam a perceção de disponibilidade para apoiar e dar feedback ao nível das aprendizagens, assim como de apoio efetivado.

A subescala Gestão Pedagógica é constituída por 10 itens que avaliam comportamentos do professor, tais como comunicação de expectativas em relação à 
performance do estudante, apresentação de tarefas significativas, competência científico-pedagógica.

Os 13 itens que constituem a subescala Contacto com os Professores avaliam até que ponto os estudantes estabelecem contacto com os professores por razões académicas.

Numa primeira fase do estudo, para os 39 itens que integravam o Questionário da Interação Professor-Estudante, os índices do teste KMO [Kaiser-Meyer-Olkin Measure of Sampling Adequacy $=.950]$, do teste de esfericidade de Bartlet [ $\chi 2$ (666) $=$ $10074,872, \mathrm{p}<.001] \mathrm{e}$ os indicadores da matriz anti-imagem (com valores na diagonal principal a oscilar entre .76 e .97) indicaram a viabilidade da análise fatorial.

Realizaram-se estudos preliminares com uma análise fatorial em componentes principais, rotação ortogonal varimax, que revelou 6 fatores com eigenvalues superiores a 1, embora de difícil interpretação. A solução forçada a 3 fatores foi a que se revelou conceptualmente mais interpretável apesar da observação do gráfico de progressão dos valores próprios (scree test) sugerir a configuração de dois fatores. Este estudo inicial revelou a necessidade de reorganização e redução do instrumento.

No processo de redução e reorganização dos dados foram realizados sucessivos ensaios, tendo sido considerados os seguintes critérios (Hair, Anderson, Tatham, \& Black), sempre ponderados em função do seu contributo conceptual para o fator:

i) foram eliminados os itens 10, 13, 32, 35, 36 por apresentarem valores das comunalidades inferiores a .30

ii) os itens 13 e 35 foram eliminados por apresentarem saturações (no fator) inferiores a .30;

iii) os itens 19,20,32 também foram eliminados por apresentarem saturações elevadas em mais que um fator (considerou-se como limite de corte saturações cuja diferença de saturação $\leq .1$ );

iv) finalmente foram ainda eliminados os itens 3 , 11,25 e 30 , considerados inadequados do ponto de vista conceptual tendo em conta o fator onde saturaram.

Foi realizada a Análise Fatorial em Componentes Principais, rotação ortogonal varimax, forçada a 3 fatores, com o conjunto dos 26 itens. Os indicadores fornecidos pelo teste KMO [KMO $=.944]$ e pelo teste de esfericidade de Bartlet $[\chi 2(325)=7191,821, \mathrm{p}<.001]$ indicaram a viabilidade da análise fatorial, o mesmo acontecendo com a matriz anti imagem com valores na diagonal principal que oscilaram entre .90 e .97 .

A solução encontrada evidenciou uma estrutura fatorial organizada em três fatores que em conjunto explicam 53.3 \% da variância (cf. Quadro 1). Após a rotação, o fator 1 apresenta um valor próprio de 5.49 e explica $21,1 \%$ da variância, o fator 2 tem um valor de 4.79 e explica $18.4 \%$ da variância e o fator 3 apresenta um valor próprio de 3.6 que explica $13.8 \%$ da variância. Os valores das comunalidades $\left(\mathrm{h}^{2}\right)$ registadas nos 26 itens variaram entre $.35<\mathrm{h}^{2}<.71$.
Quadro 1

Análise Fatorial dos 26 itens do QIPE

\begin{tabular}{|c|c|c|c|}
\hline \multirow{2}{*}{ Itens } & \multicolumn{3}{|c|}{ Fatores } \\
\hline & 1 & 2 & 3 \\
\hline $\begin{array}{l}\text { 27. Os professores explicam bem as } \\
\text { matérias. }\end{array}$ & .79 & .07 & .13 \\
\hline $\begin{array}{l}\text { 26. Os meus professores preparam bem } \\
\text { as aulas. }\end{array}$ & .77 & .03 & .10 \\
\hline $\begin{array}{l}\text { 18. Os trabalhos que os professores nos } \\
\text { propõem são úteis e pertinentes. }\end{array}$ & .72 & .24 & .07 \\
\hline $\begin{array}{l}\text { 31. Os meus professores são científica e } \\
\text { tecnicamente competentes. }\end{array}$ & .69 & .04 & .12 \\
\hline $\begin{array}{l}\text { 22. Estou satisfeito com os trabalhos } \\
\text { académicos que me são propostos } \\
\text { pelos professores. }\end{array}$ & .69 & .27 & .07 \\
\hline $\begin{array}{l}\text { 8. Os professores informam-nos daquilo } \\
\text { que temos de fazer, como fazê-lo e } \\
\text { quando fazê-lo. }\end{array}$ & .66 & .03 & .21 \\
\hline $\begin{array}{l}\text { 21. Os meus professores dão-me } \\
\text { orientações úteis sobre como } \\
\text { melhorar os meus trabalhos. }\end{array}$ & .63 & .34 & .16 \\
\hline $\begin{array}{l}\text { 34. Os professores estão interessados na } \\
\text { minha aprendizagem. }\end{array}$ & .62 & .20 & .31 \\
\hline $\begin{array}{l}\text { 37. Os meus professores } \\
\text { incentivam-nos a participar nas } \\
\text { aulas. }\end{array}$ & .61 & .20 & .30 \\
\hline $\begin{array}{l}\text { 17. Os professores respondem-nos } \\
\text { rapidamente quando temos dúvidas } \\
\text { ou questões. }\end{array}$ & .60 & .17 & .25 \\
\hline
\end{tabular}

Fator 1: Gestão da Relação Pedagógica; Valor próprio = 5.49; Variância explicada $=21.1 \%$

14. Procuro os professores, fora da sala $\begin{array}{llll}\text { de aula, para esclarecer dúvidas sobre } & .10 & \mathbf{7 4} & .17\end{array}$ os conteúdos da disciplina.

29. Procuro os meus professores nos horários de atendimento.

24. Fora da sala de aula, procuro os professores para falar sobre o meu futuro profissional ou sobre a carreira.

15. Costumo discutir, com os professores, ideias resultantes das minhas leituras.

28. Tenho professores a quem peço opiniões sobre projetos ou trabalhos que não estão relacionados com as suas disciplinas.

23. Procuro os professores para esclarecer dúvidas relativamente às regras e critérios de avaliação.

5. Procuro os professores para pedir sugestões de leitura/pesquisa em relação a um trabalho académico.

4. Costumo contactar os professores, fora da sala de aula, para pedir feedback sobre trabalhos académicos.

9. Procuro os professores para me darem uma opinião sobre a qualidade $\quad .29 \quad \begin{array}{ccc}\mathbf{. 5 6} & .25\end{array}$ do meu trabalho.

33. Aproveito as aulas para esclarecer, junto do professor, dúvidas que tenha. Fator 2: Contacto com os Professores; Valor próprio $=4.79$; Variância explicada $=18.4 \%$ 
Quadro 1

Análise Fatorial dos 26 itens do QIPE (continuação)

7. Tenho professores que sempre me apoiaram naquilo que precisei.

$.27 \quad .22 \quad .76$

6. Sinto-me à vontade para partilhar aquilo que penso e sinto com um professor.

1. Tenho professores com quem posso falar sobre assuntos pessoais.

2. A maioria dos meus professores disponibiliza-se para apoiar.

16. Sinto que há professores que se interessam por nós enquanto pessoas.

12. Consigo ter um diálogo sobre $\begin{array}{llll}\text { assuntos académicos com a maioria } & .28 & .33 & \mathbf{. 4 9}\end{array}$ dos professores.

Fator 3: Perceção de Suporte; Valor próprio = 3.6; Variância explicada $=13.8 \%$

Observando o Quadro 1 constata-se que o fator 1 é constituído por 10 itens e apresenta saturações que variam entre .60 e .79 . A maioria dos itens que compõem este fator pertenciam à subescala Gestão Pedagógica, exceto os itens 17 e 21 (eram itens da subescala Apoio Educativo) e o item 34 (pertencia à subescala Proximidade). Uma análise conceptual destes itens conduziu à reconsideração da sua posição original, passando estes a integrar o fator 1 que se passou a designar de Gestão da Relação Pedagógica.

$\mathrm{O}$ fator 2 integra 10 itens com saturações que oscilam entre .41 e .74. Este fator congrega os itens que originalmente constituíam a subescala Contacto com os Professores.

O fator 3 é constituído por 6 itens, com saturações que variam entre .49 e .76 . Este fator congrega itens que na sua origem pertenciam às subescalas Proximidade e Apoio Educativo. A análise conceptual destes itens conduziu à necessidade de reconsiderar a sua posição original, agregando-os numa só subescala que se designou de Perceção de Suporte, uma vez que o seu sentido conceptual apontava no sentido da definição de suporte social, que integra aspetos como a perceção de disponibilidade de apoio, sentimento de à vontade para procurar apoio, o ter com quem contar.

$O$ estudo da fidelidade para cada dimensão do Questionário Interação Professor-Estudante através do cálculo do coeficiente alpha de Cronbach $(\alpha)$ apresentou valores de correlação item-total superiores a .30 para todos os itens (Cronbach, 1984). Os índices de consistência interna obtidos para as três dimensões revelaram-se bastante aceitáveis (Hill \& Hill, 2009): fator $1 \alpha=.90$, fator $2 \alpha=.87$, e fator $3 \alpha=.84$ (cf. Quadro 2).

O primeiro fator, Gestão da Relação Pedagógica, integra itens que avaliam a perceção dos estudantes relativamente a comportamentos do professor ao nível da relação pedagógica. Os itens abordam aspetos como a comunicação de expectativas em relação à performance do estudante, apresentação de tarefas significativas, competência científico-pedagógica, feedback e interesse pela aprendizagem do estudante.
Quadro 2.

Consistência interna (alpha de Cronbach) do QIPE

\begin{tabular}{ccccc}
\hline Item & Média & $\begin{array}{c}\text { Desvio- } \\
\text { Padrão }\end{array}$ & $\begin{array}{c}\text { Correlação } \\
\text { Item-total }\end{array}$ & $\begin{array}{c}\alpha \text { com } \\
\text { exclusão } \\
\text { do item }\end{array}$ \\
\hline 8 & 3.57 & .79 & .60 & .89 \\
17 & 3.36 & .78 & .60 & .89 \\
18 & 3.42 & .78 & .68 & .88 \\
21 & 3.46 & .77 & .65 & .89 \\
22 & 3.20 & .78 & .65 & .89 \\
26 & 3.41 & .77 & .68 & .88 \\
27 & 3.35 & .73 & .73 & .88 \\
31 & 3.63 & .82 & .61 & .89 \\
34 & 3.40 & .76 & .64 & .89 \\
37 & 3.45 & .79 & .63 & .89 \\
\hline \multicolumn{5}{c}{ Gestão da Relação Pedagógica $\alpha=.90$} \\
\hline 4 & 2.83 & 1.04 & .60 & .86 \\
5 & 2.85 & 1.01 & .64 & .86 \\
9 & 3.22 & .86 & .60 & .86 \\
14 & 2.83 & .95 & .67 & .85 \\
15 & 2.49 & .94 & .64 & .86 \\
23 & 2.98 & .98 & .59 & .86 \\
24 & 2.39 & 1.06 & .62 & .86 \\
28 & 2.47 & 1.08 & .54 & .86 \\
29 & 2.56 & .98 & .58 & .86 \\
33 & 3.49 & .87 & .48 & .87 \\
\hline \multicolumn{5}{c}{ Contacto com os Professores $\alpha=.87$} \\
\hline 1 & 2.34 & 1.10 & .59 & .82 \\
2 & 3.39 & .90 & .65 & .81 \\
6 & 2.77 & .99 & .65 & .81 \\
7 & 3.05 & .97 & .73 & .79 \\
12 & 3.24 & .91 & .54 & .83 \\
16 & 3.26 & .94 & .58 & .82 \\
\hline \multicolumn{5}{c}{ Perceção de Suporte $\alpha=.87$} \\
\hline
\end{tabular}

O segundo fator, denominado Contacto com os Professores, inclui itens que avaliam comportamentos de contacto de natureza académica que os estudantes estabelecem com os professores.

O terceiro fator, Perceção de Suporte, integra itens que avaliam a perceção de um relacionamento de proximidade e suporte com os professores, na perspetiva do "ter com quem contar".

\section{Discussão}

Neste artigo apresentaram-se os procedimentos adotados para a construção do QIPE e os dados métricos do estudo exploratório. Efetuou-se uma análise fatorial exploratória para averiguar as componentes principais do QIPE, tendo sido obtida uma estrutura organizada em 3 fatores, com sentido conceptual, que no seu conjunto explicam $53.3 \%$ da variância.

Considerando a literatura (Hair et al., 2006), o facto de termos encontrado correlações item-total dos fatores superiores a .50 para todos os itens é um indicador de existência de níveis de consistência interna bastante aceitáveis.

No que concerne aos resultados da comunalidades todos os itens atingem valores acima de .30

Quanto aos pesos dos itens que constituem o fator, verificamos que quase todos os itens apresentam pesos fatoriais aceitáveis (superiores a .50) (Hair et al., 2006). 
O valor do alpha de Cronbach encontrado para os fatores traduz uma muito boa consistência interna (Hill \& Hill, 2009).

Os resultados obtidos neste estudo exploratório são reveladores das boas qualidades métricas deste instrumento. No entanto, concluímos pela necessidade de mais estudos que atestem as suas qualidades psicométricas do QIPE.

\section{Referências}

Cronbach, L. (1984). Essentials of psychological testing ( $4^{\text {th }}$ ed.). New York: Harper $\&$ Row.

Freire, T., \& Almeida, L. (2001). Escalas de avaliação, construção e validação. In E. Fernandes \& L. Almeida (Eds.), Métodos e técnicas de avaliação: Contributos para a prática e investigação psicológicas (pp. 109-128). Braga: Universidade do Minho, Centro de Estudos em Educação e Psicologia.

Cole, D. (2008). Constructive criticism: e role of Student-faculty inte- ractions on African American and Hispanic students' educational gains. Journal of College Student Development, 49 (6), 587-605.

Hair, J., Anderson, R., Tatham, R., \& Black, W. (2006). Multivariate data analysis $\left(6^{\text {th }}\right.$ ed.). New Jersey: Pearson Education, Inc.

Helterbran, V. (2008). The ideal professor: Student perceptions of effective instructor practices, attitudes, and skills. Education, 129 (1), 125-138.

Hill, M., \& Hill, A. (2009). Investigação por questionário. Lisboa: Edições Sílabo.

Kuh, G., Kinzie, J., Buckley, J., Bridges, B., \& Hayek, J. (2006). What matters to student success: a review of the literature. Commissioned report for the national symposium on postsecondary student success: Spearheading a dialog on student success. Symposium conducted at the meeting of the National Postsecondary Education Cooperative, Washington, DC. Retrieved from http://nces.ed.gov/npec/pdf/kuh_team_report.pdf

Pascarella, E., \& Terenzini, P. (2005). How college affects students: a third decade of research. San Francisco: Jossey-Bass.

Silva, S. (2012). Dinâmicas de envolvimento $e$ de desenvolvimento do estudante do ensino superior. Tese de Doutoramento apresentada à Faculdade de Psicologia e de Ciências da Educação da Universidade de Coimbra, Coimbra, Portugal.

Silva, S., Ferreira, J. A., \& Ferreira, A. (2011). A relação professor-estudante na perspetiva de professores e estudantes da Escola Superior de Educação de Coimbra. Cadernos de Pedagogia no Ensino Superior, $22,23-45$. 